\title{
Ouvindo Crianças Sobre Sentidos e Significados Atribuídos ao TDAH
}

\author{
Rudinei Luiz Beltrame \\ Universidade do Sul de Santa Catarina - Palhoça - SC \\ Simone Vieira de Souza \\ Universidade Federal de Santa Catarina - Blumenau - SC \\ Deise Maria do Nascimento \\ Universidade do Sul de Santa Catarina - Palhoça - SC \\ Paulo Roberto Sandrini \\ Universidade do Sul de Santa Catarina - Palhoça - SC
}

\begin{abstract}
Resumo
Cada vez mais, fenômenos de ordem cultural, social, econômica, política e comportamental são transformados em questões médicas e individuais. Logicamente, se o problema é do indivíduo, poder-se-ia tratá-lo e curá-lo, ignorando-se, assim, todo o vasto contexto problemático de desigualdades, de exclusão, de padrões e normas, de competitividade e de homogeneidade em que estamos inseridos. Na tentativa de aprofundar esse tema, o presente estudo investiga a produção de significados e sentidos por crianças/estudantes, diagnosticadas com Déficit de Atenção com ou sem hiperatividade. O estudo foi realizado com quatro estudantes entre 7 e 14 anos de idade e seus responsáveis. Como resultados, pode se destacar que todos os diagnósticos surgiram a partir de queixas oriundas da escola que levaram os familiares a buscar ajuda nos consultórios de especialistas. É necessário repensar práticas que proporcionem um desenvolvimento sem excluir a diversidade e nem patologizar a singularidade.

Palavras-chave: Transtorno da Falta de Atenção com Hiperatividade; distúrbios da aprendizagem; crianças.
\end{abstract}

\section{Listening to children about meanings and senses attributed to ADHD}

\begin{abstract}
Increasingly, cultural order phenomena, social, economic, political and behavior are transformed into medical and individual issues. Logically, if the problem is with individual power would treat it and cure it, ignoring thus the whole wide problematic context of inequality, exclusion, standards and norms, competitiveness and homogeneity which we operate. In an attempt to deepen this theme, this study investigates the production of meanings and meanings by children / students diagnosed with attention deficit with or without hyperactivity. The study was conducted with four students between 7 and 14 years of age and their parents. As a result, it can be noted that all diagnostics have emerged from complaints arising from school that led families to seek help in the offices of specialists. It is necessary to rethink practices that provide a development without excluding the diversity and uniqueness or pathologizing.
\end{abstract}

Keywords: Attention Deficit Disorder With Hyperactivity; developmental disabilities; children.

\section{Oyendo Niños Sobre Sentidos y Significados Atribuidos al TDAH}

\section{Resumen}

Cada vez más, fenómenos de orden cultural, social, económica, política y comportamental son trasformados en cuestiones médicas e individuales. Lógicamente, si el problema es del individuo, se podría tratarlo y curarlo, ignorándose, así, todo el vasto contexto problemático de desigualdades, de exclusión, de patrones y normas, de competitividad y de homogeneidad en que estamos inseridos. En la tentativa de profundizar ese tema, el presente estudio investiga la producción de significados y sentidos producidos por niños/estudiantes, diagnosticadas con Déficit de Atención con o sin hiperactividad. El estudio fue realizado con cuatro estudiantes entre 7 y 14 años de edad y sus responsables. Como resultados, se puede destacar que todos los diagnósticos surgieron a partir de quejas oriundas de la escuela que llevaron a los familiares a buscar ayuda en los consultorios de especialistas. Es necesario repensar prácticas en que proporcionen un desarrollo sin necesitar excluir la diversidad y ni considerar enfermedad a la singularidad.

Palabras clave: Trastorno de hiperactividad con falta de atención; discapacidad del desarrollo; niños. 


\section{Introdução}

As vicissitudes do processo de aprendizagem de crianças e adolescentes têm colocado o Transtorno de Déficit de Atenção/Hiperatividade (TDAH) como destaque no cenário contemporâneo das discussões sobre patologização da sociedade e da educação. Atualmente, este é um dos temas mais estudados em crianças em idade escolar. Estima-se, também, que seja um dos principais motivos de encaminhamento de crianças/estudantes aos sistemas de saúde como: serviços escolares, postos de saúde, entre outros (Landskron, \& Sperb, 2008; Santos, \& Vasconcelos, 2010).

Concomitantemente, a administração medicamentosa para o tratamento teve um sobressalto nos últimos anos. Dados da Agência Nacional de Vigilância Sanitária (ANVISA) mostram que, de 2009 a 2011, a estimativa percentual de aumento real foi de $28,2 \%$ no consumo médio mensal de metilfenidato (psicoestimulante aprovado no Brasil para o tratamento do TDAH), que gerou um gasto aproximado de $\mathrm{R} \$ 28,5$ milhões, por ano, para a população usuária (Anvisa, 2012).

Tão questionáveis quanto o uso exacerbado de medicamento são os critérios usados pelo DSM-IV para realizar o diagnóstico. Segundo Peixoto e Rodrigues (2008), tais critérios permanecem como um consenso, sem dados empíricos claros que justifiquem o número de itens requisitados para o diagnóstico de TDAH. Para Collares e Moysés (2010, p. 80), tais critérios "[...] são vagos, plenos de preconceito e, prenhes de fé e ideologia". Essas afirmações revelam a falta de objetividade e clareza nos critérios para realizar o diagnóstico de TDAH.

Da mesma forma que se localizam critérios questionáveis do ponto de vista científico, questionável é, também, a sua constituição histórica como transtorno. Embora o diagnóstico tenha sido legitimado e sua existência declarada real em um consenso internacional, sua veracidade é muito contestada. O consenso internacional, assinado em 2002, legitima o TDAH como uma condição médica real que pode ser definida como um quadro biológico da desordem, ou seja, a prova biológica da causa, mas também pode ser definida pela intensidade do dano causado ao indivíduo e à sociedade na qual ele está inserido (Caliman, 2009).

A primeira definição busca demonstrar que o transtorno é causado por aspectos biológicos, genéticos e cerebrais. Segundo Caliman (2009) e Collares e Moysés (2010), as tecnologias de imagem cerebral alimentam a crença na objetividade visual e a neutralidade dos fatos científicos. Porém, afirmam as autoras que, apesar de todas as tecnologias empreendidas, estas não são ferramentas diagnósticas autoevidentes, sendo insuficientes para comprovar a existência real do diagnóstico.

No que se refere à segunda definição, Caliman (2009) argumenta que a intensidade dos danos causados deveria ser avaliada por meio da análise dos prejuízos às atividades vitais do indivíduo (educação, relacionamentos, autonomia, aspectos profissionais, morais, econômicos, entre outros). Tais danos podem ser identificados, com facilidade, científica e clinicamente. Entretanto, será que os prejuízos causados são decorrentes de um problema localizado no indivíduo?
Ou será que estão na organização da sociedade, que não dá conta de uma diversidade humana?

Ao que tudo indica, as coisas não são tão simples como podem parecer. Referindo-se a essa definição, Caliman (2009, p. 141) afirma que "[...] a decisão sobre o que é uma consequência adversa e sobre a intensidade na qual ela se torna patológica depende do que uma sociedade acredita ser bom ou ruim, certo ou errado". A autora ainda acrescenta que a existência desta patologia não pode ser definida somente por testes cognitivos ou neurológicos, mas também pela avaliação da qualidade de vida do indivíduo e pelo risco de ameaça a esta. Ressalta-se, porém, que isso é bastante complexo, pois leva em consideração o que é avaliado e como é avaliado.

Para se entender esse movimento complexo não se pode "descolar" o indivíduo da sociedade na qual está inserido. As transformações da sociedade, principalmente com o fim do regime de acumulação fordista e o advento do neoliberalismo, trouxeram marcas profundas na forma de existência humana. As pessoas passaram a valorizar a intimidade e valorizar-se por aquilo que possuem, um "eu" precioso que precisa ser contemplado por meio da competitividade, envolto em sua subjetividade individualizada (Eidt, \& Tuleski, 2007).

Diante das exigências da sociedade pelo desenvolvimento de novas habilidades individuais, dos trabalhos cada vez mais especializados e da busca constante pela qualificação que hoje recai por completo no indivíduo, as transformações nos cenários políticos, econômicos, ético, social, cultural têm, cada vez mais, transformado em patologias características, até então, tidas como normais. Nesse sentido, podemos pensar: qual é a distinção entre uma patologia e uma busca pela otimização das habilidades atentivas requeridas, principalmente em contextos laboral e escolar? (Caliman, 2008; Collares, \& Moysés, 2010; Eidt, \& Tuleski, 2007).

Como é possível perceber, essa é uma área polêmica e permeada de controvérsias. Desde o início do século $X X$, muitas pesquisas foram realizadas sobre esse tema e quase que em sua totalidade são adultos, cientistas, pesquisadores falando sobre o assunto; porém, quantos pararam para ouvir o que as crianças e adolescentes têm a dizer sobre isso? $\mathrm{Na}$ tentativa de adentrar neste tema, o presente estudo investiga a produção de significado e sentidos produzidos por crianças/ estudantes diagnosticadas com TDAH ou déficit de atenção. Além disso, objetiva refletir sobre as implicações deste diagnóstico nas suas relações afetivas, cognitivas e sociais.

Este artigo discute sentido e significado a partir da perspectiva da Psicologia Histórico-Cultural. De acordo com Aguiar \& Ozella (2013), significados são produções históricas e sociais que permitem a comunicação e a socialização das nossas experiências. Referem-se aos conteúdos instituídos, mais fixos, que são apropriados pelos sujeitos, configurados a partir de suas próprias subjetividades e englobam uma dimensão coletiva. Já os sentidos dizem respeito à singularidade do indivíduo, representam-no; são a expressão que constitui sua subjetividade, unidade de todos os processos cognitivos, afetivos e biológicos que se articulam em sua manifestação. 


\section{Método}

Este estudo multicasos, epistemologicamente qualitativo, escutou estudantes, diagnosticados com TDAH ou déficit de atenção, para compreender como eles subjetivam o diagnóstico. A pesquisa ${ }^{1}$ foi realizada em um projeto de extensão universitária, vinculado ao Serviço de Psicologia de uma universidade comunitária do Estado de Santa Catarina. O projeto atendia crianças em idade escolar, encaminhadas pelas escolas da região da Grande Florianópolis para avaliação e atendimento a partir de uma queixa escolar.

A escolha dos participantes foi definida de acordo com os fatores de inclusão relacionados aos objetivos do estudo e o número de estudantes se deu a partir da oferta disponível no referido projeto de extensão. Foram ouvidos quatro estudantes, com idade entre 7 e 14 anos e seus respectivos responsáveis. A coleta de dados foi realizada individualmente e de forma processual, no mês de setembro de 2013. Os pais/ responsáveis, após consentirem em participar do estudo, passaram por uma entrevista semiestruturada que visava conhecer a história do estudante, assim como os processos envolvidos que culminaram no diagnóstico. Além disso, visava identificar possíveis narrativas dos pais, amigos e familiares sobre o diagnóstico de TDAH.

Após as entrevistas com os responsáveis, cada estudante que assentiu participar do estudo passou por um processo individual que consistia em identificar sentidos atribuídos ao diagnóstico, a partir das narrativas da escola e dos familiares sobre o transtorno e as implicações decorrentes do diagnóstico nas suas relações afetivas, cognitivas e sociais. O processo não teve um tempo igual para todos os participantes, sendo isto definido conforme o que fora desenvolvido no próprio curso, campo de pesquisa e encontro entre os participantes e o pesquisador. Márcio ${ }^{2}$ e Oliver participaram de três encontros, e Bolt participou de dois encontros de, aproximadamente, 50 minutos. Pê Lanza participou de apenas um encontro com um tempo aproximado de 60 minutos e não quis ir até o final da atividade. Entretanto, autorizou que se usassem as informações coletadas. Todos os encontros foram gravados e transcritos posteriormente.

Nos encontros foram usadas técnicas lúdicas como forma de acesso aos fenômenos psicológicos. A primeira atividade envolveu a composição do mapa corporal e consistia em recortar de revistas palavras ou imagens que representassem sua percepção em relação ao TDAH ou déficit de atenção. Após o recorte, os itens selecionados eram colados em um cartaz em que a silhueta da criança fora desenhada. A segunda atividade foi montar uma linha da vida, na qual os estudantes escreveram, desenharam ou realizaram colagens de aspectos (cenas) positivos e negativos que aconteceram na família e na escola, tendo como foco o diagnóstico

\footnotetext{
1 A pesquisa está cadastrada sob o $n^{\circ} 19217813.9 .0000 .5369$ e foi submetida e aprovada pelo Comitê de Ética em Pesquisa pelo parecer 403.669.

2 Os nomes usados são fictícios e escolhidos pelos estudantes participantes.
}

de TDAH. A terceira atividade consistiu na discussão das duas atividades realizadas anteriormente.

Vale ressaltar que todos os participantes, independentemente do número de encontros, realizaram as mesmas atividades com os objetivos propostos; porém, com motivações e engajamentos distintos - o que significa dizer que cada sujeito da pesquisa teve respeitado o interesse expresso no decorrer do encontro. Aos pesquisadores coube o movimento de acompanhar as narrativas, expressões corporais e não verbais, acolhendo a forma específica e singular como cada estudante se relacionava com as proposições apresentadas. O tempo definido para cada atividade foi determinado nesse cenário em que o encontro foi estabelecido. A técnica e os instrumentos são compreendidos como um caminho dinâmico, isto é, não fixo em suas prerrogativas, que estão a serviço de oferecer possibilidades de expressão e visibilidade aos fenômenos em destaque no estudo. Isso significa dizer que no registro dessa forma de pensar e fazer a pesquisa há uma escolha metodológica, pautada na epistemologia de pesquisa qualitativa, preconizada por Gonzalez Rey (2002), alinhada a uma perspectiva de pensamento da Psicologia Histórico-Cultural.

\section{Resultados e Discussão}

$\mathrm{Na}$ apresentação dos resultados, optou-se por apresentar os dados na forma cursiva, usando-se como recurso ilustrativo trechos das falas dos participantes. Os dados foram obtidos, principalmente, por meio de informações orais, sendo os materiais produzidos nos encontros um dispositivo facilitador do diálogo. O trabalho foi subdividido em duas partes: a primeira refere-se às narrativas dos familiares, dos amigos e da escola sobre o diagnóstico, acessadas, principalmente, pelo discurso dos responsáveis; a segunda refere-se aos sentidos e significados que os estudantes atribuem ao diagnóstico e às implicações deste nas suas relações sociais, cognitivas e afetivas.

\section{O que não era e que passou a ser}

Todos os estudantes têm histórias singulares; entretanto, existem aspectos comuns que atravessam suas subjetividades; dentre eles, o diagnóstico e a queixa escolar são os mais evidentes. Quanto ao diagnóstico, a maior parte dos pais que participou do estudo tem um conhecimento superficial sobre o assunto. As falas circundam em torno de: "é agitado, não para quieto" (mãe de Márcio); "não consegue se concentrar" (mãe de Pê Lanza); ou mesmo, "não entendo nada . . . nem eu sabia que ele tinha isso" (mãe de Oliver).

Quando os responsáveis são questionados sobre como foi o processo até chegar ao diagnóstico, de forma unânime todos informaram que o principal motivo foi a queixa da escola, que começou com bilhetes recorrentes na agenda escolar, passou para chamadas de pais em particular para reclamações sobre o comportamento do filho, 
até, em alguns casos, como de Bolt, haver a expulsão pela escola. Sua mãe diz que "quando ele foi para a primeira série, mudou. É obrigado a se enquadrar". Márcio também teve o diagnóstico no primeiro ano de educação formal e uma experiência semelhante. Sua mãe fala que "antes de ir para a escola não dava para perceber muita coisa, percebia que era uma criança agitada, mas eu achava normal. Depois que ele começou ir para a escola, as professoras começaram a reclamar". Oliver, devido às constantes reclamações da escola sobre seu comportamento, também foi parar em um consultório médico.

O diagnóstico pode transformar a vida do indivíduo, assim como o contexto onde ele está inserido. Conforme o relato de responsáveis por três das crianças participantes (a mãe de Oliver, a de Bolt e o pai de Pê Lanza), o relacionamento familiar mudou após o diagnóstico. Para eles, a diminuição da agitação dos seus filhos foi o principal motivador da melhora no relacionamento. Na escola também houve mudanças, principalmente na forma de perceber os estudantes. A criança deixou de ser vista como bagunceira para ser considerada doente. Novas medidas educativas e familiares passaram a ser tomadas devido a sua condição médica, o que é possível identificar no discurso da mãe de Márcio: "antes de ser diagnosticado, os professores diziam que ele era preguiçoso, que ele era 'atentado', não parava quieto... Hoje eu o vejo muito bem tratado lá, porque ele pegou o diagnóstico muito cedo".

Familiares e professores modificam suas atitudes com a criança, fazendo com que ela modifique seus comportamentos (Brzozowski, \& Caponi (2009). Genericamente, a escola se caracteriza, ainda, como um espaço de homogeneização dos comportamentos. O que se apresenta como diferente, geralmente será encaminhado a outro profissional que determinará sua normalidade ou anormalidade. Segundo as mesmas autoras, é relativamente comum professores e coordenadores fazerem diagnósticos pela observação de determinados comportamentos e solicitarem que os pais levem seus filhos para uma avaliação com um profissional da saúde.

Mesmo pessoas que possuem discernimento sobre as nuances deste suposto transtorno se veem em circunstâncias delicadas ao se defrontarem com a situação. É o que podemos perceber na fala da mãe de Bolt: "pode ser que eu esteja enganada, pode ser que não exista. Os pais ficam em uma posição horrível, porque se você não toma uma atitude, você é o irresponsável; agora, se você toma, pode ser que esteja errado". Percebe-se uma banalização da situação, em que, se não for dado o tratamento médico ao filho, os pais ou responsáveis estão negando-lhe ajuda. Essa pressão pode ser oriunda tanto da escola como dos profissionais da área da saúde, principalmente por aqueles que acreditam ser um transtorno neurológico que precisa de terapia medicamentosa.

A falta de clareza quanto ao fenômeno do TDAH ou déficit de atenção permite que diagnósticos sejam aplicados equivocadamente e apropriados rapidamente pelos pais como uma justificativa para o mau desempenho escolar. $\mathrm{O}$ discurso biomédico torna-se difícil de ser questionado por pais e professores quando coloca uma resposta à dúvida que permeia o problema. Assim, o rótulo científico é usado como estratégia para o controle subjetivo, existindo uma tendência à reprodução inquestionável do discurso do especialista por parte das mães e dos professores (Landskron, \& Sperb, 2008, Brzozowski, \& Caponi, 2009).

O saber médico desconstrói as crenças de que comportamentos, dentro desses contextos, podem ser saudáveis. Nesse sentido, temos que pensar sobre: o que há por trás de tudo isso que tem transformado crianças saudáveis em doentes?

\section{A droga da obediência}

Junto com o diagnóstico de TDAH vem a prescrição medicamentosa que consiste em psicotrópicos e estimulantes do Sistema Nervoso Central. Os quatro estudantes que participaram do estudo usaram ou ainda usam medicamento para o tratamento desse suposto transtorno. Oliver, Márcio e Bolt fazem uso de Ritalina ${ }^{\circledR}$, Pê Lanza fez uso de Imipramina durante um ano, até seu pai decidir suspender a medicação por acreditar não ser mais necessária.

No Brasil, a droga mais prescrita para o tratamento de pessoas com TDAH é o metilfenidato, comercializado com os nomes de Ritalina ${ }^{\circledR}$ e Concerta ${ }^{\circledR}$. Embora existam autores defendendo que os efeitos colaterais do uso de metilfenidato para o tratamento seja seguro, há severas críticas sobre o uso, incluindo a dependência química, a drogadição, altos níveis de toxidade e, inclusive, podendo levar à morte súbita (Collares, \& Moysés, 2010; Santos, \& Vasconcelos, 2010).

O uso da medicação para o tratamento do TDAH e/ou déficit de atenção cresceu em larga escala. Conforme Collares e Moysés (2010), o Brasil é o segundo maior consumidor deste medicamento. A adesão dos pais ao medicamento deve-se, provavelmente, à melhora da capacidade da atenção e ao controle da agitação. Entretanto, quando os pais são questionados sobre os efeitos adversos do medicamento, é possível constatar que não há uma compreensão dos familiares sobre os possíveis efeitos colaterais que este pode causar. Além disso, o uso do medicamento é a forma mais evidente de concretizar que o problema/erro é exclusivo da criança, e que o remédio irá corrigir, como o próprio nome sugere (Concerta®).

Um dado interessante de se observar é a descontinuidade do consumo do medicamento, o qual, segundo estudo da Anvisa (2012), diminui nos meses de férias. O interessante deste dado é que muitos profissionais entendem o TDAH como um transtorno neurológico e crônico. O que, então, justifica a descontinuidade do tratamento medicamentoso no período de férias? Nesse período o transtorno deixa de existir? O que determina o uso de medicamento e a sua interrupção - já que essa é uma prescrição de alguns médicos - para que a família o suspenda no período de férias? 


\section{O que dizem as vozes silenciadas?}

Não estranhem quando mencionarmos que os quatro estudantes que participaram deste estudo nunca tiveram suas opiniões ouvidas, sequer validadas por seus familiares ou pelos profissionais que Ihes aplicaram um diagnóstico. Parece ficar implícito que a menoridade os destituiu da capacidade de ponderação sobre os fenômenos que acarretam suas próprias vidas. Tentaremos apresentar, em alguns tópicos, algumas vozes que foram silenciadas há mais de 90 anos, desde a primeira classificação deste suposto transtorno.

Começaremos por um dos aspectos mais polêmicos, isto é, a medicação. Conforme apresentemos no tópico anterior, o medicamento pode melhorar a capacidade atentiva do estudante a partir da injeção de grandes quantidades de dopamina no cérebro. "Como consequência deste aumento artificial, o cérebro torna-se dessensibilizado a situações comuns da vida que provocam prazer, como alimentos, emoções, interações sociais, afetos” (Collares, \& Moysés, 2010, p. 97). Isso fica evidente na fala de um dos estudantes:

Quando eu vou me divertir, a minha mãe fala: Márcio, vai lá tomar o remédio. Aí eu não me divirto. . . Eles falam, passa a bola, passa abola, aí eu fico quieto, não jogo do jeito que eu gosto de jogar.

Outro efeito colateral causado pelo medicamento se faz presente na fala de Bolt. Ele escolheu uma figura de alimento durante a atividade do mapa corporal, pois sua mãe o chama de guloso. Quando apresenta a figura ele fala: "na minha escola não dá de comer porque minha mãe dá um remedinho pra mim. Eu preciso dele. Aí ele me deixa sem fome". Quando lhe foi perguntado sobre o motivo por que toma o "remedinho", ele afirma "minha mãe me disse que é pra eu me concentrar na lição dentro da atividade". O fato de prestar atenção na atividade para aprender não é discutido com o estudante, apenas fica evidente que ele tem dificuldade de se concentrar e, por isso, deve tomar remédio.

Oliver toma o medicamento, porém diz, claramente, que se pudesse não tomaria. Questionado se o remédio o ajuda a estudar, responde rapidamente que não. Em seguida, fala que está mais quieto na escola: "dessas duas semanas eu tomei uma anotação hoje". Quando perguntamos sobre o que mudou na sua vida depois que começou a tomar medicamento, ele, novamente, enfatiza seu comportamento na escola: "eu estou ficando mais quieto, antes eu não parava quieto". Indagado, então, se ele acha que isso é por causa do medicamento, responde que sim, mas que também foi devido à coordenação da escola. É possível perceber que, em alguma escala, o medicamento melhora a capacidade atentiva, entretanto, não há como mensurar-se a relação custo/benefício para a saúde do estudante. Por outro lado, ignora-se que a capacidade de controlar a atenção seja uma função psicológica superior, a qual o indivíduo desenvolve a partir de mediações sociais.

Para a Psicologia Histórico-Cultural, atenção, impulsividade e hiperatividade não podem ser explicadas apenas pelo ponto de vista biológico, organicista. Elas resultam de vários processos; são produto de mediações sociais complexas que não podem ser compreendidas separadas das funções psíquicas e muito menos podem ser reduzidas a uma patologia decorrente de uma disfunção neuroquímica ou de alterações neurológicas de cunho biológico.

A transição das funções psicológicas elementares para as funções psicológicas superiores é compreendida como um processo crescente, o qual vai desde sua inserção no mundo, na cultura, passando pela apropriação dos instrumentos necessários para o dia a dia, até a aquisição de conceitos mais abstratos. A constituição das funções psicológicas superiores tem como base a mediação por meio de signos, sendo a linguagem o mais importante. Assim, todas as funções inatas e involuntárias dos primeiros anos de vida (atenção, memória, percepção, pensamento, linguagem, volição, entre outras) vão sofrendo transformações por intermédio das relações sociais, desenvolvendo-se em funções sobre as quais o indivíduo adquire controle (Facci, 2004; Eidt, \& Tuleski, 2007; Legnani, \& Almeida, 2008; Vigotski, 2001).

Percebe-se, a partir das narrativas dos pais, que a função psicológica atenção foi central no diagnóstico dos quatro estudantes. As queixas estão relacionadas, principalmente, às atividades escolares. Porém, quando questionados sobre coisas que gostavam de fazer, Oliver relata ficar horas concentrado montando suas bicicletas e aparelhos de som; Márcio joga videogame com frequência e também consegue manter sua atenção concentrada na atividade. Bolt gosta de assistir a filmes e Pê Lanza gosta de brincar com seus irmãos, tocar violão, jogar videogame e escutar música. Essas são algumas atividades que os estudantes relataram que fazem e dirigem atenção concentrada à atividade. Os pais dos estudantes também confirmam essas informações. Diante desses fatos, o que acontece de diferente que em determinadas atividades há uma atenção concentrada, enquanto que em outras não há na mesma intensidade? Será que se trata de um déficit de atenção ou de uma atenção seletiva?

Para a Psicologia Histórico-Cultural, a seletividade das informações que organizam nossas ações é aprendida ao longo do desenvolvimento. No que se refere à atenção, "é importante ressaltar que a capacidade humana de selecionar estímulos mais importantes, ignorando os secundários, advém ao longo deste desenvolvimento e a partir das mediações realizadas pelos meios sociais com a criança, nos âmbitos familiar e escolar, entre outros" (Eidt, \& Tuleski, 2007, p. 239).

Portanto, além da atenção involuntária, paralelamente vão se desenvolvendo mecanismos adquiridos artificialmente, por meio das mediações sociais. Esses mecanismos dão origem a uma atenção voluntária, artificial, cultural. Isso é fundamental para a realização de determinada atividade, inclusive direcionar a atenção para estímulos mais fracos capturados pelos órgãos dos sentidos (Eidt, \& Tuleski, 2007; Legnani, \& Almeida, 2008).

Se a capacidade de selecionar estímulos mais importantes é aprendida ao longo do desenvolvimento, isto sugere que devemos repensar o que faz o estudante focar 
a atenção em determinados fenômenos. Oliver faz alguns apontamentos que nos levam a refletir sobre o assunto. Quando ele encontra a figura de um celular e conta sobre um jogo que costumava jogar com frequência no celular, questionado sobre o que há de diferente entre a manutenção da concentração no jogo comparada com outras atividades, imediatamente ele responde: "porque é um jogo, as outras coisas são chatas". Quando perguntamos, então, sobre o que acontece quando as coisas são chatas, ele responde: "aí eu não presto atenção, se eu pudesse ficar o dia na internet, no "face", joguinhos..."

Márcio também corrobora as afirmações de Oliver, ao mostrar-se um exímio jogador no jogo da memória. Com muita facilidade, ele conseguiu ter o triplo de acertos comparado com o pesquisador. Então é questionado: "como podem dizer que você tem déficit de atenção se consegue manter-se concentrado no jogo para descobrir os pares?", ele responde: "eu gosto de jogo da memória, é diferente de fazer uma coisa de que não gosto".

Coincidentemente ou não, a escola aparece no discurso desses dois estudantes como um lugar hostil. Oliver afirma: "A escola não tem nada de bom, vou porque minha mãe me obriga a ir. 95\% das crianças diriam que não gostam de ir pra escola". Márcio acrescenta: "eu não gosto de ir pra escola. Acordar todo dia de manhã é muito chato". É possível que este seja um dos motivos que podem estar imbricados na queixa de dificuldade de se concentrar e da agitação, uma vez que esta ocorre, principalmente, no âmbito escolar.

Quando gritos de resistência emergem entre os muros da escola, logo tendem a ser silenciados, em detrimento de uma prática escolar homogeneizadora, ideológica, de comportamentos socialmente aceitos. Ao criar modelos aceitáveis, tratam-se como desviantes aqueles que não correspondem aos padrões institucionalizados. Tais desvios são interpretados como um risco à coesão social; então, medidas de ajuste e correção são prescritas, na tentativa de recuperá-los para a sociedade (Moysés, 2001; Patto, 1996).

Outro aspecto do diagnóstico relacionado principalmente à escola, diz respeito à hiperatividade e à impulsividade. Com exceção de Pê Lanza, os demais estudantes têm queixas relacionadas à excessiva agitação em sala de aula. Bolt está no início da educação formal, sua mãe enfatiza que a agitação decorre de um período de transição na escola. Para ela: "na primeira série eles exigem que a criança fique sentada, faça a lição . . e uma criança como ele só queria brincar". Ela enfatiza que estava acostumada com o ritmo, pois também se declara ser uma pessoa muito agitada; porém, não se admite este tipo de comportamento na escola.

Oliver, por outro lado, diz: "eu sei que eu sou assim, é porque eu sou muito bagunceiro. Eu agito bastante, eu acho muito legal ficar na sala bagunçando". O estudante não se percebe como alguém que temum problema ou uma dificuldade para aprender. Nesta fala, é possível identificar uma fragilidade conceitual e empírica do sintoma. Para a escola, tal comportamento tende ser tratado como um problema; para o estudante, é uma diversão. Dessa forma, autores como Ritter 1982 (citado por Warner Junior, 1997, p. 160), sugerem que "esse termo seja equivocado para designar o que se propõe, já que crianças hiperativas não apresentam, necessariamente, um aumento da atividade, mas costumam estar 'fora da atividade solicitada' e fora do 'lugar adequado'”.

Da mesma forma que a atenção, no que tange a sinais de impulsividade e de hiperatividade, estes também não podem ser compreendidos isolando-se o indivíduo do meio social. Esses comportamentos estão intrinsecamente relacionados à linguagem e, no percurso do seu desenvolvimento, fala e ação se encontram de forma que o indivíduo possa se organizar internamente e externamente (Legnani, \& Almeida, 2008; Vigotski, 2001; Warner Junior, 1997).

As mediações realizadas possibilitam o processo de internalização da linguagem pela criança, o qual ocorre por meio da transição de um discurso socializado para um discurso interior. Faz parte desse processo algo denominado de fala egocêntrica, que consiste na apropriação da fala pela criança como uma forma de planejar e executar sua ação. Assim, ela passa a fazer uso da linguagem como um instrumento do pensamento e da regulação das próprias ações (Facci, 2004; Eidt, \& Tuleski, 2007; Legnani, \& Almeida, 2008; Vigotski, 2001; Warner Junior, 1997).

Sobre a descrição anterior e com base na perspectiva Histórico-Cultural, não se pode explicar a atenção, a impulsividade e a hiperatividade apenas como disfunções orgânicas, já que elas pertencem à complexa esfera da ação voluntária e da linguagem que, por sua vez, pertencem ao campo das funções psicológicas, desenvolvidas na interação com o meio. A Psicologia Histórico-Cultural apresenta uma perspectiva para a compreensão deste fenômeno, levando à reflexão de que este assunto não deve ser discutido somente no âmbito clínico, mas também no educacional, social, cultural, entre outras esferas de nossa sociedade.

Esse olhar ampliado pode ser identificado no discurso da mãe de Bolt, quando ela afirma: "penso que isso seja uma fase, não digo que ele vai tomar para o resto da vida medicação. Porque ele ainda é criança, ele não sabe se controlar". E ela continua expondo o seu exemplo: "sou uma pessoa muito agitada, só que é diferente, eu sei que tenho hora que preciso me concentrar então eu concentro, porque já tenho domínio sobre meu corpo, sobre a minha vida, quando ele crescer provavelmente vai ter domínio". Embora apresente uma coesão na sua fala, a mãe de Bolt parece não estar convencida o suficiente ao ponto de interromper o uso da medicação do seu filho, uma vez que as exigências sociais por um comportamento adequado são prevalentes.

\section{Produzindo sentidos}

Todo tipo de classificação, rótulo ou diagnóstico gera um efeito sobre o sujeito. Algumas falas dos estudantes deixam evidente como se reconhecem a partir do que os outros disseram sobre eles. Quando perguntado a Oliver o que é o TDAH, ele reproduz o discurso apresentado pela mãe, dizendo que é uma pessoa que "não consegue ficar prestando atenção nas coisas, não consegue ficar parado 
cinco minutos. Eu não consigo ficar parado cinco minutos". Em seguida, questionado sobre o que o faz ficar assim, ele novamente, volta-se para o discurso da mãe: "por causa da hiperatividade". Esta fala denuncia como as ações do indivíduo passam a ser compreendidas de uma forma determinista e fatalista.

Bolt e Márcio também nos proporcionaram recortes que fazem pensar sobre a subjetivação desse suposto transtorno. Márcio diz ter que tomar medicamento para "controlar, para concentrar". Bolt repete o discurso da mãe quando Ihe é perguntado sobre por que toma o "remedinho". Ele já foi convencido de que precisa tomar o medicamento, caso contrário, nas suas palavras: "eu não ia fazer as lições". Em outra passagem perguntamos o que as pessoas falam sobre ele, e a resposta foi: "eu sou agitado". Diante desses depoimentos, conclui-se que chegará um momento em que o fazer ou o deixar de fazer não será compreendido dentro de um contexto, mas justificado por um transtorno. Tudo que não tinha explicação passa a fazer sentido. Já o estudante, de tanto ouvir sobre como ele é, passa a se reconhecer nesse papel e a agir e pensar que realmente tem um problema, subjetivando o diagnóstico.

Outro aspecto gira em torno do constrangimento à exposição. Os três estudantes relataram que, na escola, ninguém sabe sobre o diagnóstico. Entretanto, esse não é o mesmo discurso dos pais. Todos os responsáveis têm uma relação estreita com a escola, uma vez que todos já foram chamados para ouvir reclamações sobre seus filhos, sugerindo que o assunto circula entre os professores, mas evidenciando que o fato não é discutido abertamente com o estudante e que a exposição, além do estigma, gera certo grau de constrangimento.

Esse fato pode produzir implicações no relacionamento do estudante com outros estudantes e professores. Em relação à aceitação e rejeição no ambiente escolar, Tonelotto (2002) constatou, por meio de uma escala sociométrica, que estudantes com problemas de atenção foram os mais citados por seus colegas como rejeitados e menos citados em relação à aceitação.

Outra informação muito importante - e pouco explorada - refere-se aos aspectos positivos desses estudantes. Rangel Junior e Loos (2011) constataram que $76 \%$ dos estudantes diagnosticados com TDAH percebiam-se como possuidores de uma habilidade potencial não aproveitada pela escola. Isso fica evidente no discurso dos responsáveis, os quais percebem que a aprendizagem dos seus filhos é melhor para além da escola. A mãe de Oliver diz que a aprendizagem do seu filho, em outros contextos, "é bem avançado, bem mais fácil". A mãe de Márcio pensa que "quando é coisas do interesse dele ele vai longe". A mãe de Bolt diz que, para além da escola, a aprendizagem do filho é "muito boa, ele é muito esperto. Ele observa a água, a natureza, o vento, o tempo inteiro descobrindo alguma coisa". Já os pais do Pê Lanza dizem que "ele aprende muito brincando e desenhando".

Essas falas ainda alimentam resistências tanto dos pais como dos estudantes. Quando perguntado a Oliver se a agitação e a atenção seriam motivos para um diagnóstico, ele responde: "não, ninguém é perfeito. Cada um tem uma diferença”. Em outra passagem, Márcio responde quando Ihe perguntamos se concorda com o que falam sobre ele: "Concordar, eu não concordo. Ninguém vai concordar. É ruim". Embora exista uma queixa instaurada, um problema localizado no indivíduo, ainda aparecem, em pequenos fragmentos, movimentos de resistência diante das expectativas dos adultos e da escola, quando seu comportamento não está adequado com os padrões exigidos.

Mostrar para esses estudantes que eles não se restringem à queixa foi um dos principais resultados desta pesquisa, além de fazê-los perceber que o potencial existe, mas que, muitas vezes, fica invisível diante da queixa. Compreender como as crianças subjetivam o diagnóstico abre possibilidades para intervenções assertivas e com menos danos, uma vez que as implicações deste suposto transtorno podem escamotear uma vida de fracasso, rejeição ou exclusão, nas diversas dimensões da existência.

\section{Considerações finais}

Nesta pesquisa buscamos investigar a produção de significados e sentidos produzidos por crianças/estudantes, diagnosticadas com Déficit de Atenção com ou sem hiperatividade. As narrativas sobre o diagnóstico apontam para uma informação superficial e genérica sobre no que consistem. Foi a partir da queixa escolar que o processo de diagnosticar se desencadeou. Dentro dessa forma de diagnosticar, é possível perceber uma lógica em resolver tais questões fora do âmbito da escola, isto é, por meio dos encaminhamentos, podendo isso sugerir a necessidade de repensar as práticas e os objetivos escolares nos aspectos que se relacionam ao processo de ensino-aprendizagem para atender os problemas que cercam essa instituição.

O estudo identifica a centralidade do diagnóstico na transformação da vida do estudante, de sua família, de suas relações sociais, produzindo um tipo de reflexão que se pauta no que era e o que passou a ser depois desse evento. Ele não é mais o indisciplinado, bagunceiro, desobediente; ele agora é o doente.

A análise dos dados demonstrou que os estudantes não participam dessas decisões, são vozes silenciadas, são objetos dessas práticas de diagnóstico e prescrição. Quando falam, referem-se a todas as coisas boas da infância e da juventude que o remédio Ihes tira, por exemplo, a disposição para as brincadeiras e jogos, o prazer de comer. Por outro lado, se reforçam as informações de que precisa tomar o remédio para se concentrar, e para poder, assim, "ser normal".

Nessa direção, o diagnóstico e o uso do medicamento repercutem na forma como os estudantes se reconhecem, se subjetivam a partir dessa condição. Reproduzindo o discurso de seus pais, se reconhecem com problemas, não têm atenção, não ficam quietos, têm hiperatividade, são agitados, precisam se controlar. Nessa condição perdem de vista as suas habilidades e sua capacidade que emerge em 
situações diferentes do enquadre da sala de aula, apontando para a necessidade de mudanças no ambiente escolar que inibe talentos e homogeneíza formas de ser.

Certamente, a única coisa que se pode afirmar é que este fenômeno produz incômodo, principalmente, nos outros, isto é: a escola, os familiares, os amigos, a sociedade, enfim, todos que têm limitações para compreender a diversidade. Problemas escolares que poderiam ser resolvidos com uma intervenção pedagógica são substituídos por problemas neurológicos, que precisam de uma intervenção médica e medicamentosa.

Acreditamos que este estudo tenha avançado em relação a essa problemática, entretanto, não pretendemos dar o assunto por esgotado. Alguns questionamentos se colocam como mobilizadores de futuras investigações, caso ainda tenhamos interesse em pensar e repensar o rumo para o qual estamos caminhando nas últimas décadas, quais sejam: depois de tentativas fracassadas para encontrar uma origem orgânica, evidências científicas de doenças neurológicas que comprometeriam apenas a aprendizagem, é possível confiarmos que existe uma disfunção neurológica capaz de ser localizada no sujeito? Que interesses são esses, envolvidos neste processo, que insistimos em afirmar sua existência, mesmo sem comprovações científicas fidedignas? Como repensar práticas que proporcionem um desenvolvimento sem precisar excluir a diversidade e nem patologizar a singularidade?

\section{Referências}

Aguiar, W. M. J., \& Ozella, S. (2013). Apreensão dos sentidos: aprimorando a proposta dos núcleos de significação. Revista Brasileira de Estudos Pedagógicos, 94(236), 299-322.

Agência Nacional de Vigilância Sanitária [ANVISA] (2012). Boletim de Farmacoepidemiologia, 2(2). Recuperado: 14 jun. 2015. Disponível:http://www.anvisa.gov.br/sngpc/boletins/2012/boletim_ sngpc_2_2012_corrigido_2.pdf.

Brzozowski, F. S., \& Caponi, S. (2009). Transtorno de déficit de atenção com hiperatividade: classificação e classificados. Physis, 19(4), 1165-1187.

Caliman, L. V. (2008). O TDAH: entre as funções, disfunções e otimização da atenção. Psicologia em estudo, 13(3), 559-566.

Caliman, L. V. (2009). A constituição sócio-médica do "fato TDAH". Psicologia \& Sociedade, 21(1), 135-144.

Collares, C. A. L., \& Moysés, M. A. A. (2010). Dislexia e TDAH: uma análise a partir da ciência médica. Em Conselho Regional de Psicologia de São Paulo e grupo interinstitucional queixa escolar (Orgs.), Medicalização de Crianças e Adolescentes: Conflitos silenciados pela redução de questões sociais a doenças de indivíduos. São Paulo: Casa do Psicólogo.
Eidt, N. M., \& Tuleski; S. C. (2007). Discutindo medicalização brutal em uma sociedade hiperativa. Em M. E. M. Meira, \& M. G. D. Facci (Orgs.), Psicologia Histórico-Cultural: Contribuições para o encontro entre a subjetividade e educação. São Paulo: Casa do Psicólogo.

Facci, M. G. D. (2004). A periodização do desenvolvimento individual na perspectiva de Leontiev, Elkonin e Vigotski. Cadernos Cedes, 24(62), 64-81.

Gonzalez Rey, F. (2002). Pesquisa qualitativa em psicologia: Caminhos e desafios. São Paulo: Pioneira.

Landskron, L. M. F., \& Sperb, T. M. (2008). Narrativas de professoras sobre o TDAH: um estudo de caso coletivo. Psicologia Escolar e Educacional, 12(1), 153-167.

Legnani, V. N., \& Almeida, S. F. C. (2008). A construção diagnóstica de Transtorno de Déficit de Atenção/Hiperatividade: uma discussão crítica. Arquivos Brasileiros de Psicologia, 60(1), 02-13.

Moysés, M. A. A. (2001). A institucionalização invisível: crianças-quenão-aprendem-na-escola. Campinas-SP: Mercado de Letras; São Paulo: Fapesp.

Patto, M. H. S. (1996). A produção do fracasso escolar. São Paulo: Queiroz Editor.

Peixoto, A. L. B., \& Rodrigues, M. M. P. (2008). Diagnóstico e tratamento de TDAH em crianças escolares, segundo profissionais da saúde mental. Aletheia, (28), 91-103.

Rangel Júnior, E. B., \& Loos, H. (2011). Escola e desenvolvimento psicossocial, segundo percepções de jovens com TDAH. Paidéia, 21(50), 373-382.

Santos, L. F., \& Vasconcelos, L. A. (2010). Transtorno do déficit de atenção e hiperatividade em crianças: uma revisão interdisciplinar. Psicologia: Teoria e Pesquisa, 26(4), 717-724.

Tonelotto, J. M. de F. (2002). Aceitação e rejeição: percepção de escolares desatentos no ambiente escolar. Psicologia Escolar e Educacional, 6(2), 141-148.

Vigotski, L. S. (2001). A construção do pensamento e da linguagem. São Paulo: Martins Fontes.

Warner Junior, J. (1997). Transtornos Hipercinéticos: contribuições do trabalho de Vygotsky para avaliar o significado. Tese de Doutorado em Ciências Médicas, Saúde Mental da Unicamp, Campinas-SP. 


\section{Sobre os Autores}

Rudinei Luiz Beltrame (rudinei.beltrame@hotmail.com)

Psicólogo. Universidade do Sul de Santa Catarina - UNISUL

Simone Vieira de Souza (sivieira@hotmail.com)

Doutora em Educação - UFSC. Universidade Federal de Santa Catarina - UFSC

Deise Maria do Nascimento (deisemn@uol.com.br)

Doutorado em Psicologia. Universidade do Sul de Santa Catarina - UNISUL

Paulo Roberto Sandrini (paulo.sandrini@unisul.br)

Doutorado Interdisciplinar em Ciências Humanas. Universidade do Sul de Santa Catarina - UNISUL

Trabalho aprovado pelo Comitê de Ética sob o Número: CAAE: 19217813.9.0000.5369 
